\section{RARE BOOKS AND MANUSCRIPTS SECTION}

\section{Vice-Chair/Chair-Elect}

Peter E. Hanff, Coordinator, Technical Services, The Bancroft Library, University of California, Berkeley, CA 94720

Richard G. Landon, Head, Thomas Fisher Rare Book Library, University of Toronto, Toronto, Ontario, Canada M5S 1A5

Member-at-Large (three-year term)

Donald Farren, Providence, RI 02906

Dean H. Keller, Curator of Special Collections, Kent State University Libraries, Kent, OH 44242

\section{SLAVIC AND EAST EUROPEAN SECTION}

\section{Vice-Chair/Chair-Elect}

George V. Hodowanec, Director, William Allen White Library, Emporia State University, Enporia, KS 66801
Edward Kasinec, Research Bibliographer and Librarian, Ukrainian Research Institute, Harvard University, Cambridge, MA 02138

Secretary (three-year term)

Howard M. Leich, Slavic Acquisitions Librarian, University of Illinois at Urbana/Champaign, Urbana, IL 61801

Kay L. Shaffer, Slavic Bibliographer/Cataloger, University Libraries, State University of New York at Albany, Albany, NY 12222

Member-at-Large (one-year term)

Murlin Croucher, Slavic Bibliographer, Wilson Library, University of North Carolina, Chapel Hill, NC 27514

\section{UNIVERSITY LIBRARIES SECTION}

\section{Vice-Chair/Chair-Elect}

Jean Boyer Hamlin, Librarian, Dana Library, Rutgers University, Newark, NJ 07102

Rita L. Paddock, Head of Public Services, Harvard College Library, Cambridge, MA 02138

\title{
1978 LRRT Research Competition
}

The Library Research Round Table of the American Library Association has announced its 1978 Research Competition for two $\$ 500$ awards and invites entries from all researchers. The deadline for submitting entries is April 1, 1978. The LRRT Research Development Committee is conducting and judging the Research Competition, and the decision of the committee will be announced by Jane Robbins, LRRT chairperson, prior to the 1978 Annual Conference of the ALA.

\section{Guidelines for the Research Competition}

1. All research papers submitted must represent completed research not previously published.

2. All research papers must be related in at least a general way to library and information science. Any research mode is acceptable.

3. Research papers submitted in the competition must not exceed seventy-five pages.

4. Research papers completed in the pursuit of master's and doctoral studies (e.g., theses, seminar papers, dissertations, etc.) are not eligible for entry. Research utilizing data gathered by a master's or doctoral student is eligible unless the research report is taken directly from the paper submitted for degree requirements. Papers that are spin-offs of such research are eligible for entry in the competition.

5. Papers generated as a result of a research grant or some other source of funding are eligible for entry in the competition.
6. Research papers prepared by joint investigators are eligible for entry.

7. Only one research paper per entrant will be considered in the 1978 competition; multiple entries from one entrant will not be accepted.

8. Research papers will be judged on the following points:

a. Definition of the research problem;

b. Application of research methods;

c. Clarity of the reporting of the research;

d. Significance of the conclusions, as judged by the committee.

9. The committee reserves the right to select no winning papers if in its judgment none of the papers is considered satisfactory.

10. Each winner of the competition will receive a $\$ 500$ award.

11. Winners of the competition will be expected to present their research papers at one of the LRRT Research Forum programs at the 1978 Annual Conference. In the event that the recipient of the award is unable to attend the conference, an alternate may be designated to make the presentation or the presentation may be delayed, with the approval of the committee, until a later conference.

12. The winning papers will be published by the LRRT in its research series.

To enter the 1978 LRRT Research Competition, send three (3) copies of your research report, postmarked no later than April 1, 1978, to: Robert Burr, Librarian, Crosby Library, Gonzaga University, Spokane, WA 99202. 

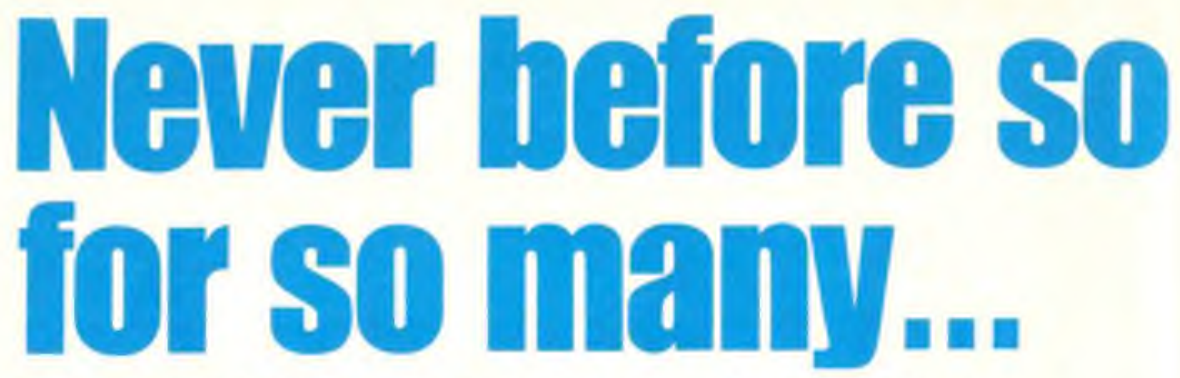

Each of the 3 Library Packages featured below offers your readers comprehensive financial and business information at a remarkable savings to you.

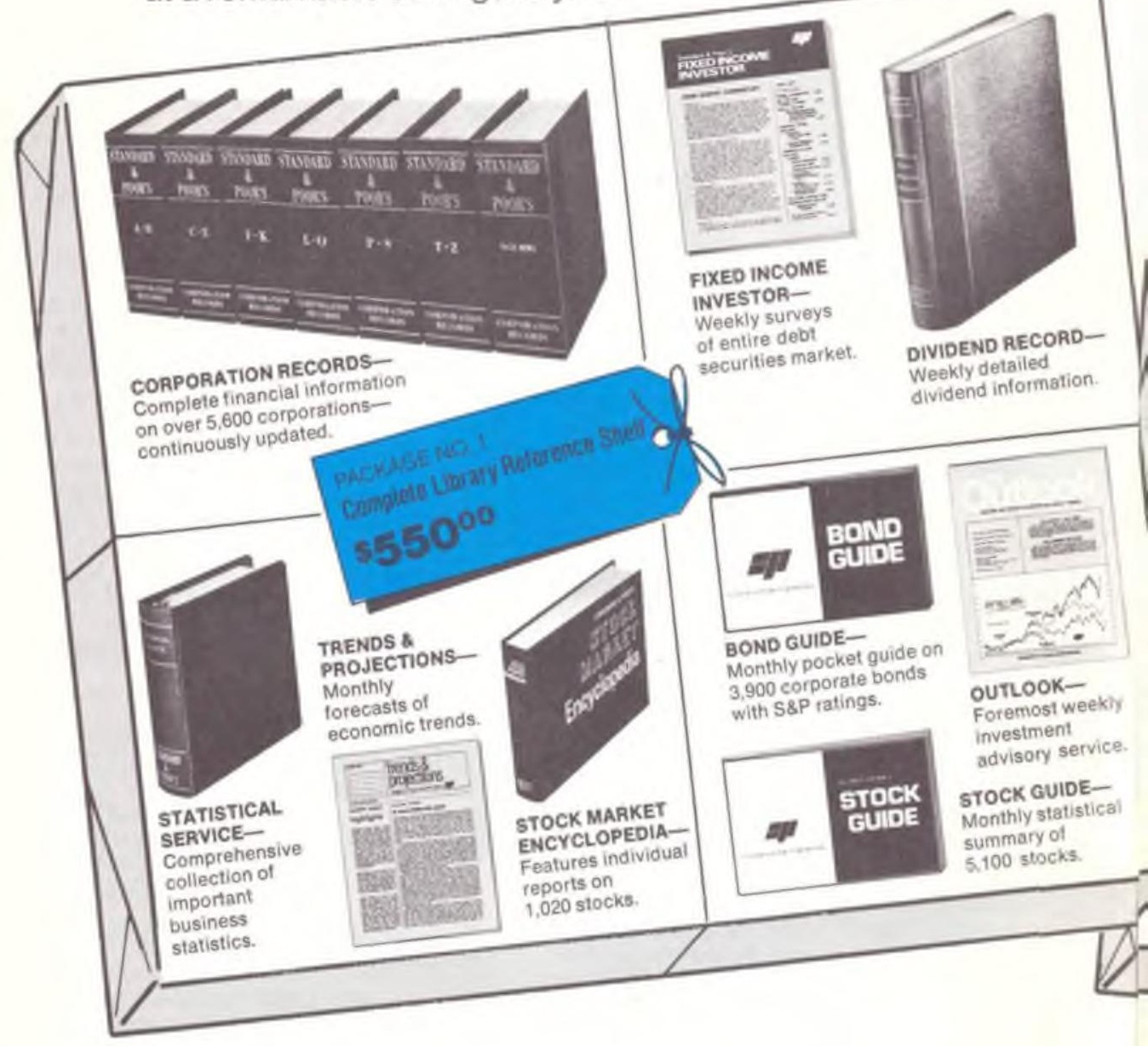




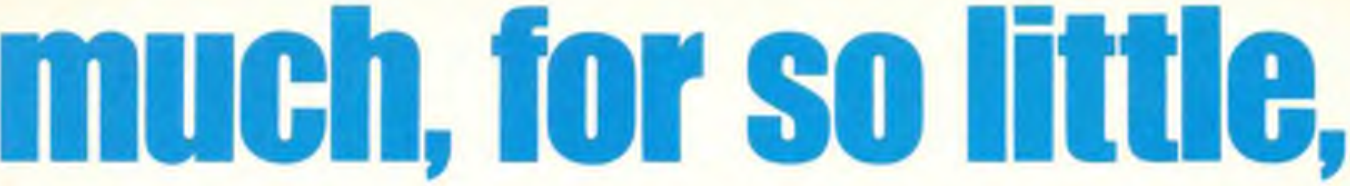

\section{Standard \& Poor's Library Packages to fit your needs, to} fit your budget. Representing an unprecedented value.

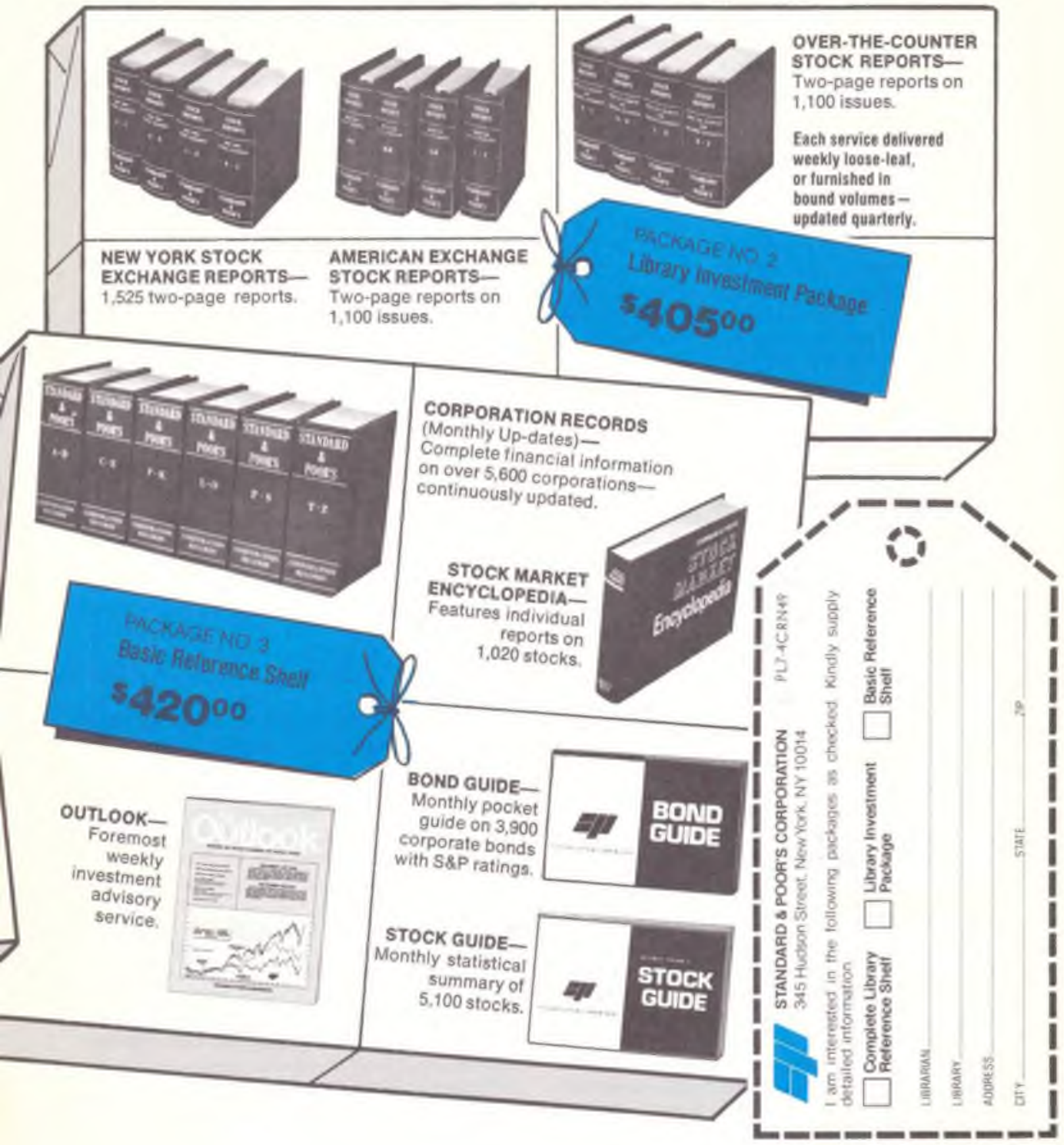

